\title{
Physician Preparedness in Response to the Coronavirus Disease 2019 Pandemic: A Cross- Sectional Study From a Developing Country
}

Laila Hashim ${ }^{1}$, Hamza R. Khan ${ }^{2}$, Irfan Ullah ${ }^{3,4}$, Maida Khalid ${ }^{5}$, Talal Almas ${ }^{6}$, Syed Muhammad Jawad Zaidi $^{7}$, Maryam Ehtesham ${ }^{6}$, Muhammad Ali Niaz ${ }^{8}$, Absam Akbar ${ }^{9}$, Abdul Haadi 10

1. Internal Medicine, Fatima Jinnah Medical University, Lahore, PAK 2. Internal Medicine, Quaid-e-Azam Medical College, Bahawalpur, PAK 3. Internal Medicine, Kabir Medical College, Peshawar, PAK 4. Internal Medicine, Naseer Teaching Hospital, Peshawar, PAK 5. Internal Medicine, Foundation University Medical College, Islamabad, PAK 6. Internal Medicine, Royal College of Surgeons in Ireland, Dublin, IRL 7. Internal Medicine, Rawalpindi Medical University, Rawalpindi, PAK 8. Surgery, Royal College of Surgeons in Ireland, Dublin, IRL 9. Internal Medicine, Aga Khan University, Karachi, PAK 10. Internal Medicine, Royal College of Surgeons In Ireland, Dublin, IRL

Corresponding author: Talal Almas, talalalmas.almas@gmail.com

\section{Abstract}

\section{Background}

December 2019 marked the inception of a global pandemic, with cases being reported worldwide. In the developing nations with scarce healthcare resources, the reliance on healthcare workers who are amply prepared to withstand the prevailing scenario is indispensable. Our study aimed to assess the level of preparedness of doctors working in various hospitals across Pakistan to combat coronavirus disease 2019 (COVID-19).

\section{Methods}

We conducted an online questionnaire-based survey in May 2020 to estimate the level of preparedness of doctors working in various departments of various private and public hospitals across Pakistan. The survey comprised 36 questions, with items evaluating the provision of adequate protective equipment, training, mental health resources, and sound collaboration between healthcare workers and the hospital management during the COVID-19 crisis.

\section{Results}

A total of 346 doctors responded to the survey, among whom $56.4 \%$ were working in public sector hospitals and $46.5 \%$ were working more than five days per week. Of those included, $87.6 \%$ were being provided with disposable gloves, but $72.8 \%$ and $43.4 \%$ of respondents professed to having no access to eye protective equipment and gowns, respectively. Only $35.3 \%$ of respondents claimed to be trained regarding the use of personal protective equipment and $28.95 \%$ were being tested. Of the physicians, $43.4 \%$ claimed to have no

Received 09/03/2020 Review began 09/09/2020 Review ended 09/09/2020 Published 09/11/2020

\section{(c) Copyright 2020}

Hashim et al. This is an open access article distributed under the terms of the Creative Commons Attribution License CC-BY 4.0., which permits unrestricted use, distribution, and reproduction in any medium, provided the original author and source are credited. proper triage system for the suspected patients and $98.3 \%$ were concerned about transmitting the disease to their family members. Of the doctors, $53.5 \%$ reported that there was sound collaboration between the hospital management and healthcare staff.

\section{Conclusion}

The survey provided evidence of inadequate delivery of personal protective equipment and training to doctors working in various hospitals across Pakistan. A sound collaboration between the hospital management and departments needs to be addressed.

Categories: Public Health, Epidemiology/Public Health

Keywords: preparedness, coronavirus disease 2019 (covid-19), doctors

\section{Introduction}

In December 2019, patients presenting with respiratory symptoms of unknown etiology were being identified in Wuhan city, Hubei province, China. The infectious agent causing unusual respiratory symptoms was identified to be a novel coronavirus or severe acute respiratory syndrome coronavirus (SARS-CoV-2) by the Chinese health authority while the world health organization (WHO) named the disease caused by this virus as coronavirus disease 2019 (COVID-19) [1]. On March 11, 2020, the WHO categorized COVID-19 as a pandemic [2].

The infectious agent responsible for causing COVID-19 is transmitted via respiratory droplets from infected individuals and remains viable on non-living objects under appropriate atmospheric conditions for several days [3]. The symptoms of COVID-19 may range from a mild to a severe presentation, causing acute 
respiratory distress syndrome (ARDS), thereby requiring mechanical ventilation [4]. The virus was confirmed to have reached Pakistan on 26 February 2020, and by 28 March, cases were registered in all four provinces of Pakistan [5].

Infected individuals can transmit the source of infection to medical professionals who are particularly prone to contracting infectious diseases even from asymptomatic patients [6]. Due to the human-to-human transmission of COVID-19, the disease is a serious threat to them, especially in developing nations like Pakistan with limited healthcare resources $[1,3]$. Healthcare workers have the responsibility of not only treating the infected patients but also of acting appropriately to manage the suspected cases and limit spread. Due to the increasing burden of cases and threats to their health, healthcare workers may be subjected to a certain level of psychological distress.

In the prevailing circumstances, the adequate delivery of protective equipment, high level of training, proper communication, and delivery of mental health facilities to the frontline doctors is of utmost importance. Our survey aimed to assess this level of preparedness among the doctors working at various departments of the hospitals in Pakistan to manage COVID-19. To the best of our knowledge, this is the first study to address the gap in knowledge regarding the level of preparedness of our frontline healthcare workers. This study can serve as important evidence to promote the delivery of protective equipment, adequate training, and mental health facilities among doctors.

\section{Materials And Methods}

A descriptive cross-sectional study was conducted during May 2020 using an online questionnaire made on Google Forms. A total of 346 doctors and post-graduate residents currently working in the various hospitals in public and private sectors across Pakistan responded to the survey. The questionnaire comprised of 36 questions, including questions regarding the demographics of study participants, the provision of personal protective equipment (PPE) and training, department/hospital preparation in dealing with COVID-19, the practice of doctors in combatting COVID-19, and the perception of doctors regarding COVID-19. The responses of the doctors to various questions were tabulated and their association across the public and private sectors was assessed using the Chi-square test. The data were eventually analyzed using the Statistical Package for the Social Sciences (SPSS) version 25 (IBM Corp., Armonk, NY).

\section{Results}

A total of 346 participants responded to the online survey. The mean age of the participants was $28.88 \pm$ 6.246 years. The demographics of the study participants are delineated in Table 1 . 


\section{Cureus}

\begin{tabular}{|c|c|c|c|}
\hline \multicolumn{2}{|l|}{ Parameters } & Frequency & Percentages \\
\hline \multirow{2}{*}{ Gender } & Male & 161 & $46.5 \%$ \\
\hline & Female & 185 & $53.5 \%$ \\
\hline \multirow{2}{*}{ Marital status } & Unmarried & 227 & $65.6 \%$ \\
\hline & Married & 119 & $34.4 \%$ \\
\hline \multirow{2}{*}{ System } & Private & 151 & $43.6 \%$ \\
\hline & Government & 195 & $56.4 \%$ \\
\hline \multirow{5}{*}{ Hospital category } & $\begin{array}{l}\text { Specialized tertiary care teaching } \\
\text { hospitals }\end{array}$ & 271 & $78.3 \%$ \\
\hline & $\begin{array}{l}\text { District/Tehsil headquarter } \\
\text { hospitals }\end{array}$ & 12 & $3.5 \%$ \\
\hline & Rural healthcare units & 4 & $1.2 \%$ \\
\hline & Private clinics & 10 & $2.9 \%$ \\
\hline & Others & 49 & $14.1 \%$ \\
\hline \multirow{5}{*}{ Job designation } & House officer & 118 & $34.1 \%$ \\
\hline & Medical officer & 39 & $11.3 \%$ \\
\hline & Postgraduate trainee & 138 & $39.9 \%$ \\
\hline & Consultant & 34 & $9.8 \%$ \\
\hline & Other & 17 & $4.9 \%$ \\
\hline \multirow{6}{*}{ Specialty } & Cardiology & 121 & $35 \%$ \\
\hline & General Surgery & 66 & $19.1 \%$ \\
\hline & Internal Medicine & 46 & $13.3 \%$ \\
\hline & Gynecology & 23 & $6.6 \%$ \\
\hline & Pediatrics & 19 & $5.5 \%$ \\
\hline & Emergency & 13 & $3.8 \%$ \\
\hline \multirow{3}{*}{ How many days of a week do you work? } & $<3$ days & 72 & $20.8 \%$ \\
\hline & 3 to 5 days & 113 & $32.7 \%$ \\
\hline & $>5$ days & 161 & $46.5 \%$ \\
\hline \multirow{2}{*}{$\begin{array}{l}\text { Is your department providing only emergency services to the patients in the } \\
\text { recent COVID-19 crisis? }\end{array}$} & No & 148 & $42.8 \%$ \\
\hline & Yes & 198 & $57.2 \%$ \\
\hline \multirow{4}{*}{ Exposure to SARS-CoV-2 } & Rarely & 63 & $18.2 \%$ \\
\hline & Occasionally & 176 & $50.9 \%$ \\
\hline & Daily & 100 & $28.9 \%$ \\
\hline & Never & 07 & $2.0 \%$ \\
\hline
\end{tabular}

TABLE 1: Demographics of study participants

SARS-CoV-2: severe acute respiratory syndrome coronavirus 2

Furthermore, results obtained from inquiring about the provision of personal protective equipment, 


\section{Cureus}

including disposable gloves and isolation gowns, and training pertaining to protective measures, methods of nasopharyngeal swab testing, and how to use and dispose of personal protective equipment, are elucidated in Table 2.

\begin{tabular}{|c|c|c|}
\hline Questions & Yes & No \\
\hline \multicolumn{3}{|l|}{ Questions regarding the provision of PPE } \\
\hline Have you been provided with eye-protective goggles in your department? & $\begin{array}{l}94 \\
(27.2 \%)\end{array}$ & $\begin{array}{l}252 \\
(72.8 \%)\end{array}$ \\
\hline Have you been provided with alcohol-based sanitizers in your department? & $\begin{array}{l}281 \\
(81.2 \%)\end{array}$ & $\begin{array}{l}65 \\
(18.8 \%)\end{array}$ \\
\hline $\begin{array}{l}\text { Have you been given training regarding protective measures to be taken while encountering a patient suspected of } \\
\text { having COVID-19? }\end{array}$ & $\begin{array}{l}122 \\
(35.3 \%)\end{array}$ & $\begin{array}{l}224 \\
(64.7 \%)\end{array}$ \\
\hline Have you been introduced to the methods of nasopharyngeal/oropharyngeal swab sampling? & $\begin{array}{l}100 \\
(28.9 \%)\end{array}$ & $\begin{array}{l}246 \\
(71.1 \%)\end{array}$ \\
\hline Have you been given training on how to use and dispose of personal protective equipment? & $\begin{array}{l}110 \\
(31.8 \%)\end{array}$ & $\begin{array}{l}236 \\
(68.2 \%)\end{array}$ \\
\hline
\end{tabular}

\section{TABLE 2: Provision of PPE and training}

PPE: personal protective equipment; COVID-19: coronavirus disease 2019

The data are expressed in the form of frequency (percentages).

The preparation levels of the various hospitals in response to COVID-19 is further tabulated in Table 3.

\begin{tabular}{|c|c|c|}
\hline Questions & Yes & No \\
\hline $\begin{array}{l}\text { Is portable imaging equipment available in your department to limit the transport of COVID-19 suspected or confirmed } \\
\text { patients? }\end{array}$ & $\begin{array}{l}196 \\
(56.6 \%)\end{array}$ & $\begin{array}{l}150 \\
(43.4 \%)\end{array}$ \\
\hline Is there sound collaboration between healthcare representatives of your department and hospital management? & $\begin{array}{l}185 \\
(53.5 \%)\end{array}$ & $\begin{array}{l}161 \\
(46.5 \%)\end{array}$ \\
\hline
\end{tabular}

\section{TABLE 3: Department/hospital preparation for COVID-19}

COVID-19: coronavirus disease 2019

Data is expressed in frequency (percentages).

Additionally, the physicians were inquired about their adaptations towards combatting the COVID-19 pandemic. In specific, they were asked about the use of an N95 mask, how frequently they change their mask, how they disinfect their equipment, and if they notify their hospital's infection prevention team or local health department when a COVID-19 suspected patient is being investigated (Table 4). 


\section{Cureus}

Parameters

Do you use an N-95 mask or higher when in close contact with a patient under investigation for COVID-19?

No

Yes

How frequently do you change the protective mask you use?

After contact with every patient

Daily

Every alternate day

Weekly

Do you disinfect your equipment (stethoscope, manometer) after contact with every COVID-19 suspected patient?

No

Do you immediately notify your hospital's infection prevention team or local health department, when a COVID-19 suspected patient is being investigated?
No
46
$13.3 \%$
Yes

TABLE 4: Physician adaptation in response to COVID-19.

COVID-19: coronavirus disease 2019

Table 5 elucidates the physicians' perception regarding the COVID-19 pandemic.

\begin{tabular}{|c|c|c|c|}
\hline Questions & Yes & No & Maybe \\
\hline $\begin{array}{l}\text { Do you think using complex personal protective equipment (PPE) increases the risk of self-contamination among } \\
\text { healthcare workers? }\end{array}$ & $\begin{array}{l}87 \\
(25.1 \%)\end{array}$ & $\begin{array}{l}94 \\
(27.2 \%)\end{array}$ & $\begin{array}{l}165 \\
(47.7 \%)\end{array}$ \\
\hline $\begin{array}{l}\text { Do you think patients with mild respiratory symptoms from COVID-19 should be isolated at home while avoiding } \\
\text { close contact with family members? }\end{array}$ & $\begin{array}{l}301 \\
(87 \%)\end{array}$ & $\begin{array}{l}28 \\
(8.1 \%)\end{array}$ & $\begin{array}{l}17 \\
(4.9 \%)\end{array}$ \\
\hline Do you think healthcare workers are subjected to significant stress during the COVID-19 pandemic? & $\begin{array}{l}335 \\
(96.8 \%)\end{array}$ & $3(0.9 \%)$ & $\begin{array}{l}08 \\
(2.3 \%)\end{array}$ \\
\hline If you exhibit any respiratory symptoms, would you continue providing care to the patients? & $\begin{array}{l}31 \\
(9.0 \%)\end{array}$ & $\begin{array}{l}250 \\
(72.3 \%)\end{array}$ & $\begin{array}{l}65 \\
(18.8 \%)\end{array}$ \\
\hline
\end{tabular}

\section{TABLE 5: Physicians' perception of the various facets of COVID-19}

COVID-19: coronavirus disease 2019

Data is expressed in frequency (percentages).

With regards to the provision of PPE, our study found that the provision of disposable gloves $(\mathrm{p}$-value $=$ 0.017 ) and the provision of isolation gown ( $p$-value $=0.012$ ) are significantly associated with the type of hospital in question (government or private). Concerning the provision of training, an introduction to the methods of nasopharyngeal/oropharyngeal swab sampling was found to be significantly associated with the type of hospital ( $\mathrm{p}$-value $=0.001$ ), as demonstrated by Table 6 . 


\section{Cureus}

Questions

Provision of PPE

Have you been provided with disposable gloves in your department?

No

Yes

Have you been provided with an isolation gown in your department?

No

Yes

Have you been provided with eye-protective goggles in your department?

No

Yes

Have you been provided with alcohol-based sanitizers in your department?

No

Yes

Provision of training

Have you been given training regarding protective measures to be taken while encountering a patient suspected of having COVID-19?

No

Yes

Have you been introduced to the methods of nasopharyngeal/oropharyngeal swab sampling?

No

Yes

Have you been given training on how to use and dispose of personal protective equipment (PPE)?

No

Yes
Private

$\begin{array}{lll}95 & 129 & \\ (42.4 \%) & (57.6 \%) & 0.532 \\ 56 & 66 \\ (45.9 \%) & (54.1 \%) & \end{array}$

$113 \quad 139$

$(44.8 \%) \quad(55.2 \%) \quad 0.461$

$38 \quad 56$

(40.4\%) (59.6\%)

$22 \quad 43$

$(33.8 \%) \quad(66.2 \%) \quad 0.077$

$129 \quad 152$

(45.9\%) (54.1\%)

$(45.9 \%) \quad(54.1 \%)$ pvalue* $^{*}$

77

$74 \quad 122$

$(37.8 \%) \quad(62.2 \%)$

$80 \quad 166<$

(32.5\%) (67.5\%) 0.001

$71(71 \%) \quad 29(29 \%)$

$101 \quad 135$

(42.8\%) (57.2\%) 0.642

$50 \quad 60$

(45.5\%) (54.5\%)

TABLE 6: Comparison between the provision of PPE across public and private sector hospitals

PPE: personal protective equipment; COVID-19: coronavirus disease 2019

Data is expressed in frequency (percentages).

${ }^{*}$ Chi-square test 
Regarding the perception of doctors, responses to the question, 'patients with mild respiratory symptoms from COVID-19 should be isolated while avoiding close contact with family members' were significantly associated with the level of qualification ( $\mathrm{p}$-value $=0.013$ ). The remaining insignificant associations are delineated in Table 7 .

\begin{tabular}{|c|c|c|c|c|c|}
\hline Questions & $\begin{array}{l}\text { House } \\
\text { officer }\end{array}$ & $\begin{array}{l}\text { Medical } \\
\text { officer }\end{array}$ & $\begin{array}{l}\text { Postgraduate } \\
\text { trainee }\end{array}$ & Consultant & $\begin{array}{l}\text { p- } \\
\text { value* }\end{array}$ \\
\hline $\begin{array}{l}\text { Do you think using complex personal protective equipment (PPE) increases the risk } \\
\text { of self-contamination among healthcare workers? (Yes) }\end{array}$ & $\begin{array}{l}29 \\
(34.1 \%)\end{array}$ & $\begin{array}{l}10 \\
(11.8 \%)\end{array}$ & $35(41.2 \%)$ & $11(12.9 \%)$ & 0.367 \\
\hline $\begin{array}{l}\text { Do you think patients with mild respiratory symptoms from COVID-19 should be } \\
\text { isolated at home while avoiding close contact with family members? (Yes) }\end{array}$ & $\begin{array}{l}96 \\
(33.6 \%)\end{array}$ & $(12.2 \%)$ & $127(44.4 \%)$ & $28(9.8 \%)$ & 0.013 \\
\hline $\begin{array}{l}\text { Do you think healthcare workers are subjected to significant stress during COVID-19 } \\
\text { pandemic? (Yes) }\end{array}$ & $\begin{array}{l}114 \\
(35.7 \%)\end{array}$ & $\begin{array}{l}39 \\
(12.2 \%)\end{array}$ & $135(42.3 \%)$ & $31(9.7 \%)$ & 0.152 \\
\hline $\begin{array}{l}\text { If you exhibit any respiratory symptoms, would you continue providing care to the } \\
\text { patients? (Yes) }\end{array}$ & $\begin{array}{l}7 \\
(24.1 \%)\end{array}$ & $\begin{array}{l}05 \\
(17.2 \%)\end{array}$ & $15(51.7 \%)$ & $02(6.9 \%)$ & 0.473 \\
\hline
\end{tabular}

\section{TABLE 7: Perception of doctors at varying designations}

PPE: personal protective equipment; COVID-19: coronavirus disease 2019

${ }^{*}$ Chi-square test

Data is expressed in frequency (percentages).

The frequencies (percentages) of doctors who responded Yes to the above-mentioned questions were tabulated.

\section{Discussion}

As a developing country, with an inadequate healthcare system, Pakistan is facing a lot of challenges amid the prevailing scenario. The overarching aim of this study was to assess the readiness of the doctors in various hospitals across Pakistan to combat the pandemic with the scarce facilities and training opportunities available. In our study population, $28.9 \%$ of healthcare workers claimed to be exposed to COVID-19 suspected patients almost daily, and $50.9 \%$ of the respondents claimed occasional exposure. Of the population, $46.5 \%$ was working for more than five days a week. These percentages reveal that a large proportion of doctors working in different health care facilities across Pakistan is predisposed to a constantly increasing number of COVID-19 suspected patients.

The healthcare professionals are jeopardized to the risk of infection due to several factors and must be provided with adequate personal protective equipment (PPE), including masks, gloves, goggles, gowns, hand sanitizers, and cleaning supplies [7-8]. A cross-sectional study including doctors in the United States and Pakistan demonstrated that $50.6 \%$ of the Pakistani doctors had been compelled to work without PPE as compared to merely $7.1 \%$ of the doctors in the US [9]. In our survey, $72.8 \%$ and $43.4 \%$ of respondents professed to have no access to eye protective equipment and gowns, respectively. Responses to the questions regarding the provision of PPE were compared among the subjects working in public and private health sectors. The results show that $60.5 \%$ of respondents from the private hospitals were not provided with adequate disposable gloves ( $\mathrm{p}$-value $=0.017$ ), indicating that these variables are related. Similarly, $51.3 \%$ of respondents from private hospitals were not provided with isolation gowns ( $\mathrm{p}$-value $=0.012$ ). These results might suggest that the difference between the provision of PPE among the public and private sectors of healthcare facilities is due to the government attempting to make sure its ample supply for the healthcare workers working in the public sector. It might also be due to increased financial strain due to which private hospitals in developing countries have difficulty in providing their healthcare workers with appropriate facilities. To ensure a better outcome during the pandemic, there is an unmet need for a sound collaboration between the private sector hospitals and government health care policymakers [8]. Many health care workers have been reported to die, with hundreds being infected with COVID-19 in Pakistan [5,10]. The satisfactory provision of PPE can, therefore, protect the healthcare workers by lessening the transmission rate, thereby reducing the stress on the vulnerable healthcare system.

An essential component of the readiness of the doctors working in various departments during the current situation is their level of training regarding protective measures to be taken while contracting a speculated patient and treating them simultaneously, the use and disposal of PPE, and the techniques of nasopharyngeal/oropharyngeal swab sampling. Our survey demonstrated that only $35.3 \%$ of the respondents were being trained properly regarding the protective measures to be taken while encountering a patient 
suspected of having COVID-19, 28.95\% being introduced to the methods of nasopharyngeal/oropharyngeal swab sampling, and $31.8 \%$ being given training on how to use and dispose off PPE. These results challenge the inclination of our front-line healthcare workers to combat the prevailing circumstance. Another study showed that about $76 \%$ of the front-line healthcare workers had some level of confidence in isolating a suspected case while $72 \%$ of respondents of the study felt somewhat confident about what and how to use PPE [11]. The disparity in these percentages signifies that the level of training of doctors in our hospitals is notably unsatisfactory regarding PPE usage. We also noted a significant difference regarding the training of nasopharyngeal/oropharyngeal swab sampling between doctors working public and private setups. Amongst the respondents, $76 \%$ serving in private hospitals were introduced to the methods of nasopharyngeal swab sampling while only $29 \%$ of doctors working in public hospitals said they knew the method, with a significant $\mathrm{p}$-value of $<0.001$, indicating that these variables were related. However, there was no statistically significant difference between the level of training regarding the use of PPE and precautionary measures to take while treating a COVID-19 suspected patient among the doctors working in the public and private sectors. Our healthcare organizations must ensure the provision of formal training and guidance to our doctors in order to make our healthcare system more qualified in contending fatal infectious diseases.

The perception level of the doctors regarding COVID-19 might be a contributing factor for adequate preparedness. Although the use of more complex PPE may increase the risk of self-contamination, only $25.1 \%$ of respondents agreed to this and $47.7 \%$ were not sure about it [12]. The results were not significantly associated with doctors working at various designations. Patients with mild COVID-19 symptoms can be isolated and managed at home while avoiding close contact with family members [13]. Of the doctors, 86.9\% agreed to this notion, with the response being statistically significant ( $\mathrm{p}$-value $=0.013$ ).

With the emergence of the COVID-19 pandemic, hospitals are compelled to propose new policies and practices among which are the introduction of proper triage systems to receive and screen suspected patients, the availability of portable imaging equipment, and sound communication among the hospital management, departments, and front-line healthcare workers [8,12]. Forty-three point four percent (43.4\%) of individuals responded that they had no triage system and portable imaging equipment in their respective departments. A triage plan enables us to designate our healthcare resources more effectively and prevents its unwarranted use [14]. Furthermore, valuable communication in times of crisis plays a pivotal part in improving the fecundity of a healthcare system, including two-way communication between front-line providers and the leadership [15]. Amongst the respondents, 53.5\% claimed sound collaboration between healthcare representatives of the respective departments and hospital management. However, a large percentage responded to the opposite. Our survey also demonstrated that $86.7 \%$ of the doctors notified their hospital's infection prevention team or local health department when a COVID-19 suspected patient was being investigated, alluding to a good reporting practice.

Front-line healthcare workers are subjected to a significant amount of strain amid the pandemic, which can be contributed to numerous factors. In our survey, $96.9 \%$ of the doctors thought that healthcare workers were subjected to significant stress during the COVID-19 pandemic. One of the factors contributing to the mental stressors among the doctors can be the fear of getting infected themselves, and $94.6 \%$ of respondents were self-monitoring themselves for signs of illness. Another major contributing factor to the level of anxiety can be the fear of transmitting the infection to family members, and $98.3 \%$ of doctors responded that they were concerned about the possibility. A study conducted in China assessed the degree of mental health symptoms among the front-line workers and reported that more than $70 \%$ of participants had psychological symptoms [16]. Providing mental healthcare is indispensable in helping our doctors overcome the psychological strains exerted by the pandemic. To monitor their mental health, physicians must be provided with adequate mental health resources. However, in our study, $85.3 \%$ of the doctors said they were not being provided with mental health and counseling resources in their departments. This might be one of the factors affecting the readiness of our doctors in combating the COVID-19 pandemic unfavorably.

Nevertheless, using an online survey distributed via various social platforms remains a limitation of our study. This can potentially explain the unequal representation of doctors in various departments across the country.

\section{Conclusions}

In Pakistan, doctors working on the frontline of the public sector amidst the COVID-19 pandemic have a better provision of PPE. Special attention should be given to private-sector doctors pertaining to the factors posing difficulties to the proper supply, demand, and use of PPE. It is also imperative to provide adequate training to the frontline workforce, along with education to improve their perceptions about the disease, training, and patient care. A large proportion of the respondents believed that doctors are under significant mental stress and the issue must be addressed appropriately by facilitating good communication and collaboration among healthcare workers, respective departments, and local health authorities. Moreover, mental health counseling resources must also be provided to doctors.

\section{Additional Information}

\section{Disclosures}


Human subjects: Consent was obtained by all participants in this study. Animal subjects: All authors have confirmed that this study did not involve animal subjects or tissue. Conflicts of interest: In compliance with the ICMJE uniform disclosure form, all authors declare the following: Payment/services info: All authors have declared that no financial support was received from any organization for the submitted work. Financial relationships: All authors have declared that they have no financial relationships at present or within the previous three years with any organizations that might have an interest in the submitted work. Other relationships: All authors have declared that there are no other relationships or activities that could appear to have influenced the submitted work.

\section{References}

1. Guo YR, Cao QD, Hong ZS, et al.: The origin, transmission and clinical therapies on coronavirus disease 2019 (COVID-19) outbreak - an update on the status. Mil Med Res. 2020, 7:11. 10.1186/s40779-020-00240-0

2. Shah K, Chaudhari G, Kamrai D, Lail A, Patel RS: How essential is to focus on physician's health and burnout in coronavirus (COVID-19) pandemic?. Cureus. 2020, 12:e7538. 10.7759/cureus.7538

3. Sohrabi C, Alsafi Z, O'Neill N, et al.: World Health Organization declares global emergency: a review of the 2019 novel coronavirus (COVID-19). Int J Surg. 2020, 76:71-76. 10.1016/j.ijsu.2020.02.034

4. Singhal T: A review of coronavirus disease-2019 (COVID-19). Ind J Pediatr. 2020, 87:281-286. 10.1007/s12098-020-03263-6

5. Saqlain M, Munir MM, Ahmed A, Tahir AH, Kamran S: Is Pakistan prepared to tackle the coronavirus epidemic?. Drugs Ther Perspect. 2020, 36:213-214. 10.1007/s40267-020-00721-1

6. Chang D, Xu H, Rebaza A, Sharma L, Dela Cruz CS: Protecting health-care workers from subclinical coronavirus infection. Lancet Resp Med. 2020, 8:E13. 10.1016/S2213-2600(20)30066-7

7. WHO. Coronavirus disease (COVID-19) outbreak: rights, roles and responsibilities of health workers, including key considerations for occupational safety and health. (2020). Accessed: June 29, 2020: https://www.who.int/docs/default-source/coronaviruse/who-rights-roles-respon-hw-covid-19.pdf? sfvrsn=bcabd401_0.

8. Shadmi E, Chen Y, Dourado I, et al.: Health equity and COVID-19: global perspectives. Int J Equity Health. 2020, 19:104. 10.1186/s12939-020-01218-z

9. CDC. Healthcare professional preparedness checklist for transport and arrival of patients with confirmed or possible COVID-19. (2020). Accessed: June 29, 2020: https://www.cdc.gov/coronavirus/2019-ncov/hcp/hcppersonnel-checklist.html.

10. Javed B, Sarwer A, Soto EB, Mashwani ZUR: Is Pakistan's response to coronavirus (SARS-CoV-2) adequate to prevent an outbreak?. Front Med. 2020, 7:158. 10.3389/fmed.2020.00158

11. Prescott K, Baxter E, Lynch C, Jassal S, Bashir A, Gray J: COVID-19: how prepared are front-line healthcare workers in England?. J Hosp Infect. 2020, 105:142-145. 10.1016/j.jhin.2020.04.031

12. Herron JBT, Hay-David AGC, Gilliam AD, Brennan PA: Personal protective equipment and Covid 19- a risk to healthcare staff?. Br J Oral Maxillofac Surg. 2020, 58:500-502. 10.1016/j.bjoms.2020.04.015

13. Chughtai AA, Khan W: Use of personal protective equipment to protect against respiratory infections in Pakistan: a systematic review. J Infect Public Health. 2020, 13:385-390. 10.1016/j.jiph.2020.02.032

14. Lai J, Ma S, Wang Y, et al.: Factors associated with mental health outcomes among health care workers exposed to coronavirus disease 2019. JAMA Netw Open. 2020, 3:e203976. 10.1001/jamanetworkopen.2020.3976

15. Maves RC, Downar J, Dichter JR, et al.: Triage of scarce critical care resources in COVID-19 an implementation guide for regional allocation. Chest. 2020, 158:212-225. 10.1016/i.chest.2020.03.063

16. Garg M, Wray CM: Hospital medicine management in the time of COVID-19: preparing for a sprint and a marathon. J Hosp Med. 2020, 15:305-307. 10.12788/jhm.3427 